\title{
Fatores que Influenciam o Processo de Doação de Leite Humano: Uma Revisão Sistemática da Literatura
}

\author{
Naiana Mota Buges ${ }^{1}$, Renata Junqueira Pereira ${ }^{2}$
}

\begin{abstract}
RESUMO
O objetivo deste estudo foi descrever os fatores que influenciam as lactantes na doação de leite humano, por meio de discussão de artigos das bases de dados Scopus, Web of Science, Lilacs e Medline, publicados a partir de 1998, quando houve a criação da Rede Brasileira de Bancos de Leite. Foram selecionados 42 artigos para análise de títulos e resumos. Após aplicados os critérios de exclusão, a revisão foi composta por 15 artigos, sendo elencados os principais fatores motivadores da doação de leite humano, dentre eles altruísmo/benevolência/resposta empática; excesso de leite e intercorrências com a amamentação; orientação, auxílio e apoio social; descentralização, estrutura e logística; paridade e escolaridade. Conclui-se que a compreensão do comportamento e dos sentimentos das lactantes em relação ao processo de doação de leite pode embasar a criação de políticas de saúde para promoção da prática da doação, aperfeiçoando as já existentes, com manutenção e captação de novas doadoras de leite humano.
\end{abstract}

Palavras-chave: Banco de leite. Leite humano. Doações. Motivação.

FACTORS THAT INFLUENCE THE BREAST MILK DONATION PROCESS: A SYSTEMATIC REVIEW OF THE LITERATURE

\section{ABSTRACT}

This study aimed to describe the factors that influence breastfeeding mothers to donate human milk by discussing articles from the Scopus, Web of Science, Lilacs and Medline databases published since 1998, when the Brazilian Human Milk Bank Network was created. We selected 42 articles for the analysis of titles and abstracts. After applying the exclusion criteria, the final review consisted of 15 articles, and we listed the main motivating factors for human milk donation, being among them: altruism/ benevolence /empathy; excess milk and complications with breastfeeding; guidance, assistance and social support; decentralization, structure and logistics; parity and schooling. We concluded that the comprehension of the breastfeeding mothers' behavior and feelings regarding the process of milk donation can base the creation of health policies to promote the practice of donation and improve existing ones, through maintenance and capture of new breast milk donors.

Keywords: Milk bank. Breast milk. Donations. Motivation.

RECEBIDO EM: $31 / 1 / 2020$

MODIFICAÇÕES SOLICITADAS EM: 29/3/2020

ACEITO EM: 3/4/2020

\footnotetext{
${ }^{1}$ Enfermeira. Mestrado em Ciências da Saúde pela Universidade Federal do Tocantins (UFT). Docente da Universidade de Gurupi (Unirg), Tocantins, Brasil. http://lattes.cnpq.br/5802206784279082.https://orcid.org/0000-0003-1222-205X.naiana_mota@yahoo.com.br

2 Doutorado em Ciência dos Alimentos pela Universidade Federal de Lavras (Ufla), Minas Gerais. Docente do Curso de Nutrição e do Programa de PósGraduação em Ciências da Saúde da Universidade Federal do Tocantins, Palmas, Tocantins, Brasil. http://lattes.cnpq.br/5178647720304213. https://orcid. org/0000-000-94874013. renatajunqueira@uft.edu.br
} 


\section{INTRODUÇÃO}

São inúmeros os benefícios e vantagens da amamentação em relação à oferta de qualquer substituto do leite materno; logo, sua promoção, proteção e apoio necessitam ser ações prioritárias entre os profissionais de saúde e em toda a sociedade (BRASIL, 2015).

Os Bancos de Leite Humano (BLH) têm se configurado como um dos mais importantes elementos estratégicos da política pública em prol da amamentação, sendo desenhados com a finalidade de funcionarem como instituições de proteção social, encarregadas de cuidar dos interesses da doadora e de seu filho, destinadas a incentivar a prática da amamentação natural - sem gerar lucro, recompensa financeira ou material atribuída à mulher pelo leite doado (ANVISA, 2008).

A Rede Brasileira de Bancos de Leite Humano (RBLH) apresenta seu modelo de crescimento baseado na descentralização aos Estados e municípios, sendo formada atualmente por $224 \mathrm{BLH}$ em funcionamento e mais 217 postos de coleta de leite humano (PCLH) (RBLH, 2020).

A partir de 1985 observou-se uma expansão dos BLHs (ANVISA, 2008; ALMEIDA, 1999) A RBHL foi criada em 1998 por ação conjunta do Ministério da Saúde (MS) e da Fundação Oswaldo Cruz (Fiocruz), desenvolvendo ações que colaboram para a diminuição da mortalidade infantil. Os BLHs buscam promover, proteger e apoiar o aleitamento materno, coletando e distribuindo leite humano (LH) de qualidade certificada, contribuindo para a redução da mortalidade infantil, somando esforços ao Pacto Nacional pela Redução da Mortalidade Infantil e Neonatal (RBLH, 2013).

A RBLH brasileira é considerada a maior e mais complexa do mundo pela Organização Mundial de Saúde (OMS). Nessa rede, os BLHs e os PCLHs são responsáveis pela promoção do aleitamento materno e execução das atividades de coleta, processamento e controle de qualidade do LH produzido nos primeiros dias após o parto, leite de transição e leite maduro, para posterior distribuição sob prescrição (FIOCRUZ, 2017).

A OMS aconselha que as crianças sejam alimentadas exclusivamente com leite materno (LM) nos primeiros seis meses de vida, e que a amamentação seja mantida até os dois anos de idade ou mais, juntamente com o uso de alimentos complementares apropriados (RBLH, 2013).
Considerando-se que a doação de LH depende única e exclusivamente da solidariedade humana, os aspectos que permeiam a percepção das puérperas sobre esse processo necessitam ser mais bem compreendidos, no sentido de fornecerem subsídios para o convencimento de mulheres a se tornarem doadoras, para a manutenção dessa prática por aquelas que já doam e para a criação de estratégias e políticas de captação e incremento do número de doadoras.

Neste contexto, o objetivo desta revisão foi elencar e descrever os fatores que influenciam as lactantes no ato de doação de $L H$, por meio de revisão da literatura científica publicada a partir de 1998, quando houve a criação da RBLH no Brasil.

\section{MÉTODOS}

O presente estudo seguiu os procedimentos metodológicos descritos na literatura, a qual emprega métodos sistemáticos e explícitos para identificar, selecionar e avaliar criticamente as pesquisas já publicadas acerca da temática, segundo a metodologia descrita por Preferred Reporting Items for Systematic Reviews and Meta-Analyses (Prisma) do tipo Experiencial (GALVÃO; PANSANI; HARRAD, 2015; MUNN et al., 2015).

Durante a elaboração deste estudo, percorreram-se as seguintes etapas: 1) estabelecimento da questão de pesquisa; 2 ) seleção dos descritores; 3 ) escolha das bases de dados; 4) definição dos critérios de inclusão e exclusão dos estudos; 5) categorização dos estudos; 6) avaliação dos estudos; 7) interpretação dos resultados e 8) síntese do conhecimento.

Estabeleceu-se a seguinte questão norteadora: "Quais são os fatores que influenciam as lactantes no ato de doação de LH? A revisão foi realizada nos artigos originais disponíveis nas bases de dados Sci Verse Scopus Top Cited (Scopus), Web of Science e Biblioteca Virtual em Saúde (BVS), que abrange duas outras bases de dados: Literatura Latino-Americana e do Caribe em Ciências da Saúde (Lilacs) e Medical Literature Analysis and Retrieval System On-line/PubMed (Medline).

A busca ocorreu durante o mês de novembro de 2018 em artigos publicados entre 1998 e 2018, nos idiomas português, inglês e espanhol. Foi utilizada a terminologia em saúde consultada nos Descritores em Ciências da Saúde (Decs) e no Medical Subject Headings (MeSH), pelos quais se identificaram os respectivos descritores: Milk Banks (Banco de Leite); Human milk (Leite humano); Donations (doações); Motivation 
(Motivação), Breastfeeding (Aleitamento materno). A combinação dos descritores foi realizada por meio dos operadores booleanos AND e OR.

Inicialmente, a identificação dos artigos foi realizada pelo título das publicações encontradas nas bases de dados, conforme a estratégia de busca estabelecida. Em caso de dúvida, foi realizada leitura do resumo e metodologia do estudo. Após esta fase de refinamento, foi realizada leitura dos resumos ou dos artigos, na íntegra, para identificação dos que fariam parte da revisão.

Foram encontradas 951 publicações e, como critérios de inclusão, foram contemplados artigos provenientes de pesquisas originais, nos idiomas inglês, português ou espanhol, que contemplassem a questão de pesquisa. $O$ recorte temporal estabelecido foi em razão da expansão dos BLHs, que ocorreu a par- tir de 1998 com a criação da RBLH brasileira. Foram aplicados filtros de ano, tipo de documento e idioma. Sendo assim, 909 documentos foram excluídos por não serem artigos, não estarem nos idiomas selecionados ou estarem fora do recorte temporal. $O$ total para a análise de títulos e resumos foi de 42 artigos. Nesta etapa, foram excluídos os artigos que não eram de pesquisas originais, além daqueles que não se relacionavam com a temática estudada tampouco com a questão de pesquisa. Foram excluídos também aqueles estudos que abordavam as questões específicas de análise laboratorial e microbiológica do LH.

No caso de artigos duplicados nas bases de dados, estes foram considerados apenas uma vez. A revisão final foi composta por 15 artigos. Para melhor ilustrar a busca e os motivos de exclusão dos estudos, construiu-se um fluxograma (Figura 1).

Figura 1 - Processo seleção dos estudos incluídos na revisão

Estudos identificados nas bases de dados a partir dos descritores elencados:

"Milk Banks; milk, human; Donations;

Motivation, Breastfeeding", novembro de 2018.
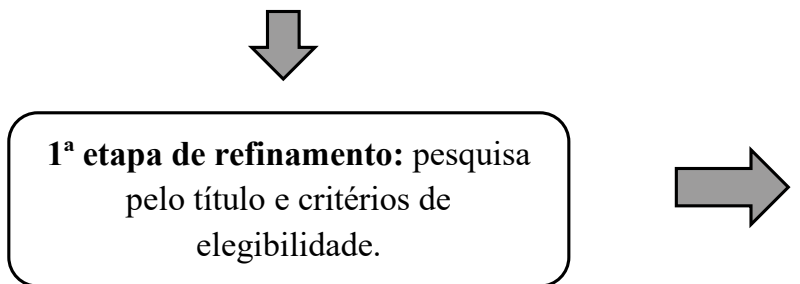

Estudos para leitura do texto completo/resumo:

(n: 42)

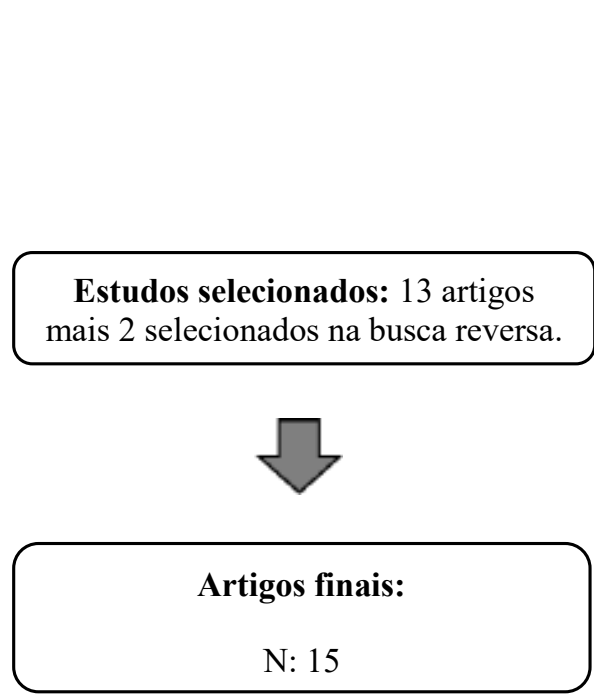

Estudos excluídos: (n: 27)

Artigos repetidos: 19;

Profissional de saúde como amostra: 1;

Revisão sistemática: 1; 


\section{RESULTADOS}

A amostra final da revisão foi composta por 15 artigos. Os estudos tiveram como população-alvo doadoras e ex-doadoras de $\mathrm{LH}$, lactantes não doadoras e genitoras de recém-nascidos (RN) pré-termo.

Os temas principais, relacionados aos resultados, foram classificados em fatores que dificultam e fatores que estimulam a doação.

A seguir citam-se alguns fatores destacados nos estudos como de impacto negativo na perspectiva e no ato de doar LH: dificuldades na ordenha; separação física dos neonatos; falta de informação na atenção básica à saúde; desinformação de maneira geral; medo; dificuldade com a amamentação; crenças sobre quantidade e qualidade do leite; falta de informação sobre existência de BLH e função dos lactários; indisponibilidade de tempo; emoções negativas impactando na produção de leite; distância para transportar o leite; falta de apoio à amamentação no trabalho; falta de orientação às mulheres acerca dos cuidados com as mamas ou da possibilidade de doação; e não divulgação do papel do BLH pelos serviços de saúde.
Como fatores associados ao estímulo à doação de LM, temos: recebimento de orientação e incentivo dos profissionais de saúde; preocupação com os RNs que necessitam da ajuda; disponibilização de depósito de coleta de LH nas comunidades; aumento no número de equipes para coletar LM nas residências; facilidade e rapidez no processo; compreensão do benefício do LM; sentimento de altruísmo e benevolência; desejo pessoal; estar em ambiente onde são socialmente envolvidas, apoiadas e aceitas; garantia de não desperdício do LM; excesso de produção de LM; ser multípara; telefone e fôlder como meio de comunição para incentivar a doação; crença da necessidade de ordenha do excedente de LM para manutenção da produção; conhecimento das vantagens para a mulher doadora; a utilização do seu leite após a pasteurização; e busca pelo BLH após problemas relativos à amamentação, principalmente ao ingurgitamento mamário.

Uma síntese dos principais resultados dos estudos relacionados aos fatores que influenciaram o ato de doação de LH pode ser visualizada no Quadro 1.

Quadro 1 - Síntese dos principais resultados dos estudos relacionados aos fatores que influenciaram $\mathrm{O}$ ato de doação de LH

\begin{tabular}{|c|c|c|c|}
\hline AUTOR/ANO/ PAÍS & OBJETIVOS & $\begin{array}{l}\text { TIPO DE ESTUDO/ } \\
\text { AMOSTRA }\end{array}$ & RESULTADOS (fatores de influência) \\
\hline $\begin{array}{l}\text { Meneses; Oliveira; } \\
\text { Boccolini/2017/Brasil }\end{array}$ & \begin{tabular}{|l|} 
Estimar a prevalência e \\
analisar os fatores associados \\
à doação de LM em unidades \\
básicas de saúde, a fim de \\
aumentar as reservas do BLH. \\
\end{tabular} & $\begin{array}{l}\text { Transversal/695 } \\
\text { mães de crianças } \\
\text { menores de um } \\
\text { ano, em unidades } \\
\text { com PCLH. }\end{array}$ & $\begin{array}{l}\text { Ter sido incentivada a doar LM. } \\
\text { Receber ajuda da unidade para amamentar. } \\
\text { Receber orientação sobre ordenha das mamas. } \\
\text { Internação em unidade neonatal. }\end{array}$ \\
\hline $\begin{array}{l}\text { Mackenzie; } \\
\text { Javanparast; } \\
\text { Newman/2013/ } \\
\text { Austrália }\end{array}$ & \begin{tabular}{|l|} 
Explorar o conhecimento e \\
atitudes das mães em relação \\
aos BLHs, para informar o \\
desenvolvimento de políticas \\
e diretrizes para o setor de \\
LH no sul da Austrália. \\
\end{tabular} & $\begin{array}{l}\text { Qualitativa/12 } \\
\text { mães que estavam } \\
\text { amamentando e/ } \\
\text { ou tiveram bebês } \\
\text { prematuros ou } \\
\text { doentes. }\end{array}$ & $\begin{array}{l}\text { Apoiaram a doação, desde que fosse fácil e não } \\
\text { consumisse muito tempo. } \\
\text { Usariam um BLH se tivessem certeza de que o } \\
\text { LM era seguro e apropriado para seus bebês. }\end{array}$ \\
\hline $\begin{array}{l}\text { Alves et al./2016/ } \\
\text { Portugal }\end{array}$ & $\begin{array}{l}\text { Avaliar a percepção dos pais } \\
\text { sobre os fatores que auxiliam } \\
\text { ou dificultam o fornecimento } \\
\text { de LH a prematuros extremos } \\
\text { de unidades neonatais. }\end{array}$ & $\begin{array}{l}\text { Transversal/120 } \\
\text { mães e } 91 \text { pais } \\
\text { de prematuros } \\
\text { extremos } \\
\text { internados. }\end{array}$ & $\begin{array}{l}\text { Facilitadores: contribuição para o crescimento } \\
\text { e bem-estar infantil e o conhecimento dos pais } \\
\text { sobre os benefícios da amamentação. } \\
\text { Barreiras: preocupações relacionadas à } \\
\text { inadequação da oferta de LM, dificuldades na } \\
\text { expressão do LM e separação física dos bebês. }\end{array}$ \\
\hline $\begin{array}{l}\text { Osbaldiston/2007/ } \\
\text { Estados Unidos }\end{array}$ & $\begin{array}{l}\text { Fornecer uma abordagem } \\
\text { mais quantitativa e completa } \\
\text { da doação de LH. }\end{array}$ & $\begin{array}{l}\text { Quantitativo/87 } \\
\text { doadoras e } 19 \text { não } \\
\text { doadoras. }\end{array}$ & $\begin{array}{l}\text { Razões para doar altruístas e benevolentes. } \\
\text { Processo de ordenha não pareceu problemático. } \\
\text { Doadoras em ambientes onde são socialmente } \\
\text { envolvidas, apoiadas e aceitas eram mais } \\
\text { propensas a doarem grandes volumes de LM. }\end{array}$ \\
\hline
\end{tabular}




\begin{tabular}{|c|c|c|c|}
\hline $\begin{array}{l}\text { Azema; Callahan/2003/ } \\
\text { França }\end{array}$ & $\begin{array}{l}\text { Caracterizar população de } \\
\text { doadoras de LH. }\end{array}$ & $\begin{array}{l}\text { Quantitativo/103 } \\
\text { mulheres doadoras }\end{array}$ & $\begin{array}{l}\text { Doadoras eram mulheres em idade fértil em } \\
\text { média, com forte apoio em casa. } \\
\text { Quase a metade não trabalhava fora de casa; } \\
\text { da mesma forma, um grande número atuava } \\
\text { profissionalmente na área de saúde e serviços } \\
\text { sociais. Razões para doação foram altruístas } \\
\text { e prevaleceu atitude geral otimista entre as } \\
\text { participantes. }\end{array}$ \\
\hline $\begin{array}{l}\text { Machado/2015/ } \\
\text { Espanha }\end{array}$ & $\begin{array}{l}\text { Conhecer as experiências, } \\
\text { crenças, motivações e } \\
\text { dificuldades em relação à } \\
\text { doação de LH de um grupo } \\
\text { de mulheres doadoras do } \\
\text { BLH de Granada-Andaluzia. }\end{array}$ & $\begin{array}{l}\text { Descritivo com } \\
\text { abordagem } \\
\text { qualitativa/7 } \\
\text { mulheres } \\
\text { doadoras. }\end{array}$ & $\begin{array}{l}\text { Perfil das doadoras com nível universitário, } \\
\text { casadas e com um ou dois filhos. } \\
\text { A informação sobre doação foi recebida } \\
\text { principalmente no processo de hospitalização } \\
\text { na maternidade, não abrangendo a rede de } \\
\text { atenção pré-natal ou centros de saúde. } \\
\text { Principais problemas para que as mães } \\
\text { decidissem não doar LM: desinformação, } \\
\text { distância a percorrer para transportar o LM } \\
\text { doado; falta de apoio à amamentação no } \\
\text { trabalho. } \\
\text { Principais fatores para se tornarem doadoras: } \\
\text { desejo pessoal, reconhecimento das vantagens } \\
\text { e qualidade nutricional do LM; altruísmo; } \\
\text { excesso de produção de LM (evitar o } \\
\text { disperdício). }\end{array}$ \\
\hline $\begin{array}{l}\text { Thomaz et al./2008/ } \\
\text { Brasil }\end{array}$ & $\begin{array}{l}\text { Identificar fatores que } \\
\text { influenciaram ou motivaram } \\
\text { mulheres a doarem LH para } \\
\text { um BLH em Alagoas, Brasil. }\end{array}$ & $\begin{array}{l}\text { Transversal/737 } \\
\text { doadoras. }\end{array}$ & $\begin{array}{l}\text { Maioria das doadoras havia vivenciado entre } \\
4 \text { e } 7 \text { gestações e possuía Ensino Superior } \\
\text { completo. } \\
\text { Fatores que favoreceram a doação: receberam } \\
\text { "incentivo de um profissional de saúde" e } \\
\text { reconheceram "as necessidades dos bebês que } \\
\text { os BLHs servem". } \\
\text { Fatores que dificultaram a doação: } \\
\text { disponibilidade de PCLH nas comunidades; } \\
\text { número reduzido de equipes para coleta de LM } \\
\text { nos domicílios. }\end{array}$ \\
\hline $\begin{array}{l}\text { Azema; Callahan; } \\
\text { Walburg/2007/França }\end{array}$ & $\begin{array}{l}\text { Explorar o conhecimento } \\
\text { da população feminina } \\
\text { francesa sobre a existência } \\
\text { de lactários e sobre os } \\
\text { motivos para doação de LM. }\end{array}$ & \begin{tabular}{|l|} 
Transversal/50 \\
estudantes do \\
sexo feminino, \\
uma população \\
de 47 mães que \\
amamentam e uma \\
população de 19 \\
mães doadoras \\
\end{tabular} & $\begin{array}{l}\text { Fatores que favoreceram a doação: razões ou } \\
\text { crenças altruístas relacionadas à quantidade de } \\
\text { LM. } \\
\text { Obstáculos: medo, dificuldades com a } \\
\text { amamentação, bem como as crenças sobre a } \\
\text { quantidade ou a qualidade do LM; necessidade } \\
\text { de maiores informações sobre a existência e } \\
\text { função dos lactários. }\end{array}$ \\
\hline $\begin{array}{l}\text { Alencar; Seidl/2009/ } \\
\text { Brasil }\end{array}$ & $\begin{array}{l}\text { Descrever as características } \\
\text { do comportamento de } \\
\text { doação e identificar razões, } \\
\text { crenças e sentimentos } \\
\text { relativos a essa prática, } \\
\text { com base nos relatos de } \\
\text { mulheres doadoras. }\end{array}$ & \begin{tabular}{l|} 
Exploratório, \\
descritivo e \\
transversal/36 \\
mulheres doadoras \\
e ex-doadoras.
\end{tabular} & $\begin{array}{l}\text { Razões para doação: altruísmo e excesso de } \\
\text { produção de LM. } \\
\text { O contato telefônico com o BLH foi o meio } \\
\text { mais comum de comunicação e obtenção de } \\
\text { informações para doação. }\end{array}$ \\
\hline Gribble/2014/Austrália & $\begin{array}{l}\text { Conhecer as motivações } \\
\text { para doações a BLH. }\end{array}$ & $\begin{array}{l}\text { Descritiva/97 } \\
\text { doadoras }\end{array}$ & $\begin{array}{l}\text { Razões para doação: oportunidade de ajudar; } \\
\text { resposta empática; garantia de que o excesso } \\
\text { de LM não seria desperdiçado; crença de que } \\
\text { ordenhar é necessário para a manutenção da } \\
\text { produção de LH. }\end{array}$ \\
\hline
\end{tabular}




\begin{tabular}{|c|c|c|c|}
\hline Alves/2013/Brasil & $\begin{array}{l}\text { Ressignificar os valores } \\
\text { relacionados ao ato } \\
\text { de doação de LM, que } \\
\text { emergem nas tramas } \\
\text { simbólicas imaginárias } \\
\text { das mulheres/nutrizes; } \\
\text { Compreender o sentido } \\
\text { das estruturas imaginárias } \\
\text { valorativas que se revelam } \\
\text { na ação das mulheres } \\
\text { doadoras. }\end{array}$ & \begin{tabular}{|l} 
Estudo \\
fenomenológico, \\
com abordagem \\
qualitativa/11 \\
mulheres/nutrizes.
\end{tabular} & $\begin{array}{l}\text { As instituições de saúde não informam ou } \\
\text { orientam as mulheres acerca dos cuidados } \\
\text { com as mamas ou da possibilidade de doação } \\
\text { do LM, seguindo somente protocolos e rotinas } \\
\text { institucionais (foi denunciado que algumas } \\
\text { maternidades, consultórios médicos e postos de } \\
\text { saúde não divulgam a possibilidade da doação } \\
\text { do LH, só falam sobre o amamentar como um } \\
\text { processo fácil para qualquer mulher). } \\
\text { O profissional de saúde na orientação para } \\
\text { doação de LH não valoriza a mulher/nutriz, visto } \\
\text { que não fornece a informação acerca desta } \\
\text { possibilidade na maternidade. } \\
\text { Os serviços de saúde, que atuam diretamente } \\
\text { com as mulheres e seus familiares no período } \\
\text { gravídico-puerperal, não divulgam o real papel } \\
\text { do BLH, suas vantagens para a mulher doadora } \\
\text { e a utilização do seu leite após a pasteurização. }\end{array}$ \\
\hline $\begin{array}{l}\text { Alburqueque /2017/ } \\
\text { Brasil }\end{array}$ & $\begin{array}{l}\text { Demonstrar o significado da } \\
\text { doação na percepção das } \\
\text { doadoras. }\end{array}$ & $\begin{array}{l}\text { Descritivo, } \\
\text { exploratório, } \\
\text { de abordagem } \\
\text { qualitativa/18 } \\
\text { mulheres } \\
\text { cadastradas em } \\
\text { BLH. } \\
\end{array}$ & $\begin{array}{l}\text { Evidenciou-se a necessidade de divulgação dos } \\
\text { significados para motivar as mulheres a serem } \\
\text { doadoras de LH. }\end{array}$ \\
\hline Santos/2009/Brasil & $\begin{array}{l}\text { Conhecer o perfil } \\
\text { socioeconômico das } \\
\text { doadoras de leite do BLH } \\
\text { do Hospital Universitário de } \\
\text { Londrina, Paraná. }\end{array}$ & $\begin{array}{l}\text { Transversal, } \\
\text { observacional/91 } \\
\text { mulheres que } \\
\text { doaram leite. }\end{array}$ & $\begin{array}{l}\text { Os resultados mostraram que } 65,1 \% \\
\text { procuraram o BLH por apresentarem problemas } \\
\text { relativos à amamentação, principalmente } \\
\text { por ingurgitamento mamário, e, a partir do } \\
\text { atendimento, passaram a ser doadoras de LM. } \\
\text { As demais (34,9\%) procuraram exclusivamente } \\
\text { pelo interesse em doar seu leite. }\end{array}$ \\
\hline
\end{tabular}

Fonte: Dados da Pesquisa.

\section{DISCUSSÃO}

Os fatores mais frequentemente mencionados nos estudos como estimulantes da doação de LH foram o altruísmo, a benevolência e a resposta empática. A atitude de se colocar no lugar de outras mães, que estariam passando por dificuldades dessa natureza, colaborou para a sensibilização das mulheres para a doação de LH. Percebe-se, também, que a valorização que as doadoras conferiram ao seu semelhante foi fator de destaque, quer seja o RN receptor, a outra mãe ou o próprio filho da doadora (ALENCAR; SEIDL, 2009)

A doação de leite justifica-se, em alguns casos, pela identificação com o sentimento da genitora receptora. Dentre as razões que levaram as mães a procurar o BLH, a mais citada foi saber que o banco precisava de doações $(39,71 \%)$, isto é, apresentava demanda por parte de mães e crianças que, por alguma razão, não estavam realizando aleitamento ao seio (MACHADO et al., 2009). Outros estudos também sugeriram o altruísmo - ato que beneficia outro indi- víduo, solidariedade, ato voluntário, não remunerado - como um dos principais motivos apontados para a doação de LH (ALENCAR; SEIDL, 2009; GRIBBLE, 2014)

Os resultados encontrados nesta revisão ainda alinham-se com o estudo realizado por Osbaldiston e Mingle (2007), que mostra que $92 \%$ das mulheres doadoras, por excesso na produção do leite, iniciaram o processo de doação.

Em estudo qualitativo, realizado com $11 \mathrm{mu}$ Iheres doadoras voluntárias de um BLH em Fortaleza - CE -, foi encontrado que o principal motivo para a doação do leite foi o ingurgitamento mamário e a procura pelo $\mathrm{BLH}$, em razão do desconforto ocasionado pelo congestionamento venoso e linfático da mama e pela estase láctea. Ao buscarem o serviço, as nutrizes recebiam informações sobre a seriedade do trabalho na unidade e sobre os benefícios proporcionados pelo seu leite aos receptores, manifestando-se mais dispostas a dar seguimento à doação por preocupação com a saúde dos outros RN (GALVÃO; VASCONCELOS; PAIVA, 2006). 
Em estudo realizado por Julyeth et al. (2017) com 50 doadoras de um hospital da Região Nordeste do Brasil, $40 \%$ das entrevistadas alegaram que o estímulo à produção de mais leite foi um fator determinante para a doação de LM, e o excesso da produção láctea foi o segundo maior motivo para a doação.

Estudos citam falhas dos serviços de saúde no incentivo à doação, no auxílio para amamentar, na orientação para a ordenha e no esclarecimento sobre o papel dos BLHs (MACHADO et al., 2009; ALENCAR; SEIDL, 2010), e destacam que os serviços de saúde que atuam junto as mulheres e seus familiares no ciclo gravídico-puerperal não divulgam a real função dos BLH, suas vantagens para a doadora e como se dá o emprego do leite doado após a pasteurização. Essa falha no processo de informação em saúde gera dúvidas e incertezas nas puérperas quanto ao desperdício do leite doado (ALENCAR; SEIDL, 2010). As orientações, quando acontecem, ocorrem mais no ambiente da maternidade, não contemplando as unidades de saúde que realizam o acompanhamento pré-natal (MACHADO et al., 2009).

Por outro lado, Pereira et al. (2008) demonstraram, em seu estudo, que a distribuição de fôlderes informativos pelos profissionais de saúde foi um incentivo para que as lactantes se tornassem doadoras. Outros estudos também apontaram a importância da orientação, do auxílio e do apoio profissional no processo de doação (OSBALDISTON; MINGLE, 2007; MENESES; OLIVEIRA; BOCCOLINI, 2017).

No processo de captação de doadoras, a literatura sugere que o apoio das pessoas importantes no convívio da mulher estimula o ato de doação (AZEMA; WALBURG; CALLAHAN, 2007).

Rechia et al. (2016) afirmam que as orientações sobre a doação, os procedimentos para a ordenha, a coleta e o armazenamento do LH podem empoderar as lactantes, tornando-as confiantes e capazes de resolverem as principais dificuldades com o aleitamento, além de conscientizá-las sobre a importância do LM e do ato de doar. Para tanto, os profissionais de saúde devem estar capacitados e atentos em relação às instruções normativas dos órgãos superiores em saúde, e também identificar qual a demanda de seu público por informações.

A literatura mostrou, ainda, que o número reduzido de profissionais capacitados e aptos a orientar as lactantes pode ser um fator limitante (ALVES, 2013; THOMAZ et al., 2018). Acredita-se que ações relacionadas ao apoio, à promoção e à proteção ao aleitamento materno, durante o pré-natal, possam influenciar positivamente, sensibilizando as gestantes e puérperas à doação de LH.

A humanização dos atendimentos institucionais, permeada por ações de aperfeiçoamento do processo de comunicação, acompanhada pela integração com pessoas significativas do convívio da doadora, pode contribuir para fortalecer a rede de doação de LH, facilitando a fidelização dessas voluntárias, inclusive em outras gestações (ALENCAR; SEIDL, 2010). Deve-se considerar também que as doadoras desempenham um papel multiplicador junto aos seus relacionamentos sociais, distribuindo informações e valores que beneficiam o engajamento de novas doadoras.

Machado et al. (2009) expõem que a falta de apoio à amamentação, quando do retorno ao trabalho fora do domicílio, também figurou dentre os fatores limitantes da doação, pois pode dificultar os processos de ordenha, de coleta e de armazenamento do $\mathrm{LH}$, uma vez que não se dispõe de ambiente adequado. Além disso, torna-se mais difícil o transporte do leite ordenhado para o PCLH/BLH, e o afastamento da criança pode gerar menor estímulo de sucção, ocasionando a diminuição da produção láctea, com consequências negativas para doação.

A descentralização dos ambientes de doação, com aumento do número de PCLH, parece facilitar o acesso de nutrizes à condição de doadoras. Da mesma forma, o maior número de equipes para captação do leite ordenhado nas residências das nutrizes, aumenta o número de doadoras.

O país conta hoje com $224 \mathrm{BLH}$, a maioria localizada na Região Sudeste (42\%), seguida da região Nordeste (23,2\%); Sul (16\%); Centro-oeste (12\%) e Norte $(6,8 \%)$ e $217 \mathrm{PCLH}$. No entanto, a rBLH ainda desenvolve política no sentido de ampliar esses números (RBLH, 2020).

A iniciativa de descentralização do serviço dos BLH, por meio da disposição de PCLH, deve ser provocada e apoiada, pois esses postos, além de facilitarem o transporte do LH pelas nutrizes, influenciam diretamente a doação, uma vez que recebem o leite ordenhado no domicílio das doadoras, realizam a parceria e o intercâmbio do LH com o BLH mais próximo. Além disso, os PCLH figuram também como instituições que promovem orientações no manejo da amamentação, ofertam assistência ao aprendizado dos cuidados no processo de expressão do leite e podem propiciar aumento no número de doações. 
Em estudo realizado com profissionais de saúde atuantes em BLH, dentre as principais dificuldades relacionadas à manutenção dos estoques de leite no BLH, estão a falta de transporte para realização das coletas nas residências; a resistência das mães em serem doadoras; a difícil obtenção de frascos para coleta do leite, que são arrecadados por doação; e a falta de recipientes para o armazenamento do leite no BLH (SANTOS et al., 2018).

Outro fator apontado como dificultador do processo de doação, seria o tempo dispendido no processo, sendo que as mulheres gostariam que ele fosse mais rápido e simples, conforme aponta estudo' realizado com 28 mulheres, cadastradas no BLH do Hospital São Sebastião, em Viçosa/MG, que cita a existência de serviço de coleta domiciliar de LH como um facilitador no processo de doação. No entanto, esse mesmo estudo traz como dificuldade encontrada durante o processo, a falta de tempo para realização da ordenha e para os cuidados de higiene necessários (MIRANDA, 2017).

Dois estudos apontaram que as doadoras eram, em sua maioria, mulheres multíparas. No entanto, as mulheres em questão, experimentavam pela primeira vez $\mathrm{o}$ ato de doar, supondo que poderiam ter sido doadoras nas experiências gestacionais anteriores e que não o fizeram por desinformação e falta de inciativa (MACHADO et al., 2009; THOMAZ et al., 2018).

Estudos com mulheres doadoras e ex-doadoras de LH demonstraram uma amostra composta, predominantemente, por primíparas (71,93\%) (ALENCAR; SEIDL, 2009; MACHADO et al., 2009). Esses achados mostram que a prática da doação também pode ocorrer simultaneamente a primeira experiência com a maternidade.

Assim, destaca-se o papel da equipe de saúde enquanto disseminadora de informações e conhecimento acerca do processo de doação de LH ainda no período pré-natal, com o objetivo do empoderamento das gestantes e puérperas para que possam optar por serem doadoras.

Infere-se, ainda, que a inexperiência com a amamentação, o sentimento de insegurança em relação ao processo de aleitamento do próprio filho, além das intercorrências que podem surgir, levam as nutrizes a buscar auxílio nos BLHs, quando encontram a oportunidade de se tornarem doadoras.

Sabe-se que o nível de escolaridade da mulher é diretamente proporcional ao tempo de duração da amamentação. De forma análoga, dois estudos revisados aqui demonstraram a maioria das doadoras com
Ensino Superior completo. Nesse sentido, pode-se inferir que o grau de instrução da doadora figura como fator facilitador da doação, uma vez que torna melhor a compreensão da prática do aleitamento materno, dos procedimentos de doação e da importância destes para todos os RNs (MIRANDA, 2017).

\section{CONCLUSÃO}

O comportamento de doação e os sentimentos envolvidos no processo apontam para a necessidade de criação de políticas públicas de saúde que objetivem promover a prática da doação por meio do aperfeiçoando das ações já instituídas nesse sentido.

Tanto a captação de novas doadoras quanto a manutenção das já existentes, também parecem depender desse tipo de ação promotora. Ações educativas e de apoio social que contemplem todo o período gravídico-puerperal, quando realizadas com qualidade e humanização, são fundamentais para a sensibilização das nutrizes e para a captação de novas doadoras, além de influenciarem no tempo em que as lactantes permanecem doando LH.

\section{REFERÊNCIAS}

ALBUQUeRQUE, M. M.; BARBOSA, N. R.; FERREIRA, C. B.; PINTO, E. A. Human milk donation: the meaning in donor perception. Nursing, v. 20, n. 225, p.1580-1583, 2017. Disponível em: https://pesquisa.bvsalud.org/portal/resource/ pt/biblio-869189. Acesso em: 18 out 2018.

ALENCAR, L. C. E.; SEIDL, E. M. F. Doação de leite humano e apoio social: relatos de mulheres doadoras. RLAE, v. 18, n. 3, p. 381-389, 2010. Disponível em: http://www.revistas. usp.br/rlae/article/view/4166. Acesso em: 17 out. 2018.

ALENCAR, L. C. E.; SEIDL, E. M. F. Doação de leite humano: experiência de mulheres doadoras. Rev. Saúde Pública, v. 43, n. 1, p. 70-77, 2009. Disponível em: http:// www.scielo.br/scielo.php?script=sci_arttext\&pid=s0034-89102009000100009http://www.scielo.br/scielo.php?script=sci_arttext \&pid=S0034=89102009000100009-\&lngen. Acesso em: 11 jan. 2019.

ALMEIDA, J. A. G.; MAIA P. R. S.; NOVAK, F. R. Os bancos de leite humano como suporte para a redução da mortalidade infantil: a experiência brasileira. Montevideo: Sociedad Uruguaya de Pediatria, 2004. Disponível em: http://www. bvsam.cict.fiocruz.br/evcientif/2culm/2culm.htm. Acesso em: 2 jul. 2018.

ALMEIDA, J. Amamentação: um híbrido natureza-cultura. Rio de Janeiro: Fiocruz; 1999.

ALVES, V. H. Banco de leite humano na perspectiva da muIher doadora. Revista da Rede de Enfermagem do Nordeste, v. 14, n. 6, p. 1.168-1.176, 2013. Disponível em: http://repositorio.ufc.br/bitstream/riufc/11339/1/2013_art_vhaalves.pdf. Acesso em: 16 out 2018. 
ANVISA. AGÊNCIA NACIONAL DE VIGILÂNCIA SANITÁRIA. Banco de Leite Humano: Funcionamento, Prevenção e Controle de Riscos. Disponível em: <http://www.redeblh.fiocruz.br/media/blhanv2008.pdf>. Acesso em: 12 set. 2017.

AZEMA, E.; WALBURG, V.; CALLAHAN S. C. La méconnaissance des lactariums en Francelgnorance of French milk banks. Journal de Pédiatrie et de Puériculture, v. 20, n. 7, p. 285-288, 2007. Disponível em: https://www.sciencedirect. com/science/article/pii/S0987798307001296. Acesso em: 10 nov. 2018.

BRASIL. Aleitamento materno e alimentação complementar. Brasília: Ministério da Saúde. Secretaria de Atenção à Saúde. Departamento de Atenção Básica, 2015. 120 p. Disponível em: http://bvsms.saude.gov.br/bvs/publicacoes/ saude_crianca_aleitamento_materno_cab23.pdf. Acesso em: 2 jul. 2018.

BRASIL. Banco de leite humano: funcionamento, prevenção e controle de riscos. Brasília: Agência Nacional de Vigilância Sanitária, 2008. 9 p. Disponível em: http://www.redeblh. fiocruz.br/media/blhanv2008.pdf. Acesso em: 4 jul. 2018.

FIOCRUZ. Fundação Oswaldo Cruz. Banco de leite humano. Rio de Janeiro, 2017. Disponível em: https://portal.fiocruz. br/banco-de-leite-humano. Acesso em: 22 set. 2018.

GALVÃO, M. T. G.; VASCONCELOS, S. G.; PAIVA, S. S. Mulheres doadoras de leite humano. Acta Paul. Enferm., v. 19, n. 2, p. 157-161, 2006. Disponível em: http://www.scielo.br/scielo.php?script=sci_arttext\&pi$\mathrm{d}=$ S0103-21002006000200006\&lng=en. Acesso em: 17 out. 2018.

GALVÃO, T. F.; PANSANI, T. S. A.; HARRAD, D. Principais itens para relatar revisões sistemáticas e meta-análises: a recomendação Prisma. Epidemiol. Serv. Saúde, v. 2, n. 2, p. 335-342, 2015. Disponível em: http://www.scielo.br/scielo.php?script=sci_arttext\&pi$\mathrm{d}=$ S2237-96222015000200335\&lng=en. Acesso em: 18 out. 2018.

GRIBBLE, K. D. "I'm Happy to Be Able to Help:" Why Women Donate Milk to a Peer via Internet-Based Milk Sharing Networks. Breastfeeding Medicine, v. 5, p. 1-6, 2014. Disponível em: https://www.liebertpub.com/doi/abs/10.1089/ bfm.2014.0009?rfr_dat=cr_pub\%3Dpubmed\&url_ver=Z39. 88-2003\&rfr_id=ori\%3Arid\%3Acrossref.org\&journalCode $=b f m$. Acesso em: 3 out. 2018.

INSTITUTO FERNANDES FIGUEIRA. Rede Brasileira de Banco de Leite Humano. Rio de Janeiro: Fiocruz, 2018. Disponível em: http://www.iff.fiocruz.br/index.php/8-noticias/537-rblh-brtecnologia. Acesso em: 18 dez. 2018.

JULYETH, N. A. et al. Doação de leite materno: fatores que contribuem para esta prática. Arq. Ciênc. Saúde, v. 24, n. 2, p. 14-18, 2017. Disponível em: http://www.cienciasdasaude.famerp.br/index.php/racs/article/download/548/684/. Acesso em: 17 out. 2018.

MACHADO, R. S. et al. Experiencias de donación de leche humana en Andalucía-España: un estudio cualitativo. Rev. Enfermeria Global, v. 37, n. 1, p. 114-124, 2009. Disponível em: http://scielo.isciii.es/pdf/eg/v14n37/docencia1.pdf. Acesso em: 14 out. 2018.
MACKENZIE, C.; JAVANPARAST, S.; NEWMAN, L. Mothers' knowledge of and attitudes toward human milk banking in South Australia: a qualitative study. J Hum Lact., v. 29, n. 2, p. 222-229, 2013. Disponível em: https://pubmed.ncbi.nlm. nih.gov/23515087/. Acesso em: 15 out 2018.

MENESES, T. M. X.; OLIVEIRA, M. I. C.; BOCCOLINI, C. S. Prevalência e fatores associados à doação de leite para postos de recebimento de leite humano de Unidades Básicas de Saúde, J. Pediatria, v. 93, n. 4, p. 382-388, 2017. Disponível em: http://www.scielo.br/scielo.php?script=sci_arttext\&pi$d=$ S0021-75572017000400382\&lng=en. Acesso em: 17 out. 2018.

MIRANDA, J. O. A. Doação de leite humano: investigação de fatores sociodemográficos e comportamentais de mulheres doadoras. Revista da Associação Brasileira de Nutrição, v. 8, n. 1, p. 10-17, 2017. Disponível em: https://www.rasbran. com.br/rasbran/article/view/475/152. Acesso em: 15 out. 2018.

MUNN, Z. et al. What kind of systematic review should I conduct? A proposed typology and guidance for systematic reviewers in the medical and health sciences. BMC Med Res Methodol., v. 18, n. 1, p. 5, 2015. Disponível em: https:// www.ncbi.nlm.nih.gov/pmc/articles/PMC5761190/. Acesso em: 11 jan. 2018.

OSBALDISTON, R.; MINGLE, L. A. Characterization of human milk donors. Journal of Human Lactation, v. 23, n.4, p. 350357, 2007. Disponível em: https://journals.sagepub.com/ doi/abs/10.1177/0890334407307547. Acesso em: 14 out. 2018.

PEREIRA, C. G. et al. How and why to be human milk donor? A descriptive study. Brazilian Journal of Nursing, North America, v. 7, n. 3, p. 1-5, 2008. Disponível em: http://www.objnursing.uff.br/index.php/nursing/article/ view/j.1676-4285.2008.1774/425. Acesso em: 3 out. 2018.

RECHIA, F. P. N. S. et al. Fatores que interferem na doação de leite humano: revisão integrativa. Cogitare Enferm., v. 21, n. 3, p. 1-11, 2016. Disponível em: http://www.saude. ufpr.br/portal/revistacogitare/wp-content/uploads/sites/28/2016/12/44723-189431-1-PB.pdf. Acesso em: 17 out. 2018.

RBLH. Rede Brasileira de Bancos de Leite Humano. Bancos de leite humano no tempo. Rio de Janeiro, 2013.Disponível em: http://www.redeblh.fiocruz.br/cgi/cgilua.exe/sys/start. htm?infoid=1618\&sid=368. Acesso em: 22 ago. 2018.

RBLH. Rede Brasileira de Bancos de Leite Humano. Bancos de leite humano - localização e relatórios. 2020. Disponível em: http://www.redeblh.fiocruz.br/cgi/cgilua.exe/sys/start. htm?sid=393 Acesso em: 30 mar. 2020.

SANTOS, J. C. et al. Banco de leite humano: facilidades e dificuldades para manutenção do estoque. Rev. E-Ciência, v. 6, n. 1, p. 23-30, 2018. Disponível em: http://www.revistafjn.com.br/revista/index.php/eciencia/article/view/04/ PDF\%20353. Acesso em: 16 out. 2018. 